\title{
Padrões de uso dos meios de comunicação no Brasil e seu impacto sobre níveis de informação política
}

\author{
Patterns of media use in Brazil and their impact on political \\ information levels
}

\section{Wladimir G. Gramacho André Jácomo}

\section{Resumo}

O uso de repertórios midiáticos que incluem a internet está associado a maiores níveis de informação política no Brasil. Essa é a principal conclusão deste artigo, cujo argumento organiza-se em três etapas. A primeira descreve o cenário de fragmentaçáo da audiência brasileira e identifica os seis padróes de uso dos meios de comunicação no país, com base em análise de cluster sobre dados da Pesquisa Brasileira de Mídia 2015. A segunda indica as características socioeconômicas predominantes em cada padráo de uso da mídia. E a terceira analisa a influência desses diferentes repertórios midiáticos sobre os níveis de informação política dos brasileiros, com base num modelo de regressão logística ordinal.

\section{Palavras-chave}

Pesquisa Brasileira de Mídia 2015; Padróes de Uso; Informação Política; Brasil.

\begin{abstract}
The use of media repertoires that include internet is associated with higher levels of political information policy. This is the main conclusion of this article, whose argument is organized in three stages. The first describes the scene of the Brazilian audience fragmentation and identifies the media usage patterns in the country based on cluster analysis using data from the Brazilian Media Survey 2015. The second indicates the socio-economic characteristics prevailing in each pattern of media use. Finally, the third one examines the influence of these different media repertoires on levels of political information among Brazilians, based on an ordinal logistic regression model.
\end{abstract}

\section{Keywords}

Brazilian Media Survey 2015; Patterns of Use; Political Information; Brazil. 


\section{Introdução ${ }^{1}$}

As sociedades contemporâneas experimentam, neste momento, etapas diferentes de transformação de seus sistemas midiáticos, com a introdução de novas tecnologias de comunicação e informação e a ampliação do acesso à internet. Segundo a União Internacional de Telecomunicaçóes (UTI, 2014), o Brasil ocupa uma posição intermediária no ranking mundial de usuários de internet como proporção populacional. Em estágio final, encontram-se países desenvolvidos, notadamente os escandinavos, com ao menos $95 \%$ de cidadãos usuários do novo meio. Na etapa inicial, concentram-se majoritariamente dezenas de naçóes africanas, onde menos de um décimo da população utiliza a internet. $\mathrm{O}$ caso brasileiro situa-se a meio caminho, como em outros países em desenvolvimento da América do Sul, do Leste Europeu e do Mediterrâneo ${ }^{2}$, em que aproximadamente metade da população já se tornou usuária da internet.

A incorporação desse meio digital cria novos "repertórios midiáticos" (HASEBRINK e DOMEYER, 2012), que podem oferecer experiências muito distintas daquelas predominantes nas eras da imprensa escrita, do rádio e da TV aberta. Uma exposição cotidiana e moderada à TV aberta e ao rádio, por exemplo, ilustra um padrão de uso muito diferente do convívio diário e intenso com a internet, marcada por sua interatividade, múltiplas possibilidades de escolha.

A coexistência de diferentes repertórios midiáticos e suas respectivas agendas tende a aprofundar a fragmentação de audiências. Mas também tende a diferenciá-las em questóes relevantes para o exercício de sua cidadania? Mais especificamente, a formação de diferentes repertórios midiáticos influencia a distribuição desigual de informação política?

Prior (2007) argumenta que o surgimento da internet encerra uma etapa atípica na história da comunicação política, em que uma proporção muito grande de cidadáos foi impactada por um número restrito de veículos, fenômeno característico do período hegemônico da TV aberta. Antes disso, a exposição à informação política

\footnotetext{
${ }^{1}$ Versóes preliminares deste artigo foram apresentadas no VI Congresso Wapor América Latina (Santiago, Chile), no IX Encontro da Associação Brasileira de Ciência Política (Brasília), no Seminário do Laboratório de Pesquisa em Comportamento Político, Instituiçóes e Políticas Públicas da UnB (Brasília) e em evento do Grupo de Pesquisa de Opiniâo Pública da UFMG (Belo Horizonte), todos em 2014. Os autores agradecem por comentários e sugestóes dos assistentes a esses eventos, bem como são gratos aos dois pareceristas anônimos da revista que ajudaram a aprimorar este texto com suas críticas e questóes. Lapsos remanescentes são de inteira responaabilidade dos autores.

${ }^{2}$ Exemplos do primeiro grupo são Venezuela, Colômbia e Costa Rica; do segundo, Bulgária, Sérvia e Romênia; e do terceiro, Marrocos, Tunísia e Turquia.
} 
impunha maiores custos monetários ou cognitivos e estava a cargo de maior número de emissores, fossem rádios ou jornais impressos. Com a ajuda das imagens da TV e a exibição de noticiários no horário nobre, poucos canais puderam concentrar a atenção de proporçóes muito expressivas de cidadáos em diferentes países facilitando e ampliando níveis de informação e interesse político (PRIOR, 2007) ${ }^{3}$. A internet tem alterado drasticamente esse cenário, ampliando as possibilidades de escolha da audiência e criando, segundo o autor, uma força centrífuga para longe da política.

Este artigo pretende revisitar esse debate, a partir do caso brasileiro. O argumento está organizado em três etapas, destinadas a: (i) descrever o cenário de fragmentaçáo da audiência brasileira no momento atual ao identificar os diferentes padrôes de uso dos meios de comunicação no Brasil; (ii) descrever as características sociodemográficas predominantes em cada padrão; e (iii) analisar a influência de diferentes "repertórios midiáticos" sobre os níveis de informação política dos brasileiros. O caso brasileiro, ademais, oferece uma oportunidade rara para observar se e como diferentes "repertórios midiáticos" podem estimular comportamentos distintos, uma vez que os dados a serem analisados mantém constantes o entorno institucional e o contexto temporal.

O referencial empírico deste estudo é a edição 2015 da Pesquisa Brasileira de Mídia (BRASIL, 2014), survey formado por 18.312 entrevistas feitas e amostras representativas das 27 unidades da federação e, com a aplicação de um fator de ponderação, representativas também da população brasileira.

As próximas seções apresentam: (i) uma revisão da literatura sobre transformaçôes tecnológicas do contexto midiático e sua relevância política, bem como as hipóteses de trabalho deste artigo; (ii) os resultados da análise de cluster que propóe a classificaçáo da populaçáo brasileira quanto a seus padrôes de uso dos meios de comunicação e a descrição dos clusters em termos sociodemográficos; (iii) as implicaçôes dessa fragmentação de repertórios midiáticos sobre os níveis de informação política dos brasileiros; e (iv) as principais conclusões deste estudo, bem como a indicação de suas limitaçôes e de tópicos de uma agenda futura de pesquisas neste campo.

O propósito deste trabalho, portanto, é explorar uma dimensão muito específica da ampla agenda de pesquisa e debates ligada à internet. Há já uma fragmentada literatura que se dirige a diferentes objetos de pesquisa nessa área, como as reflexôes que se orientam a compreender mudanças macrossociais derivadas da introdução das novas tecnologias (CASTELLS, 2005; CARDOSO, 2005), a refletir

\footnotetext{
${ }^{3}$ No caso brasileiro, o período hegemônico da TV aberta ocorreu nas décadas de 1980 e 1990.
} 
sobre os adequados esforços de regulação e governança sobre essa nova modalidade de interação social (LOADER, 1997), a explorar possíveis avanços na prestação de serviços de governo eletrônico (DINIZ et al., 2009; MEDEIROS E GUIMARÃES, 2006), ou até mesmo a discutir as transformaçóes no funcionamento da democracia com a ampliação com acesso à internet (GOMES, 2005a). Este artigo aspira a oferecer uma contribuição muito específica nesse quadro geral, orientada a descrever o estado atual das audiências midiáticas no Brasil e o efeito do uso da internet sobre níveis de informação política.

\section{Transformação das audiências e niveis de informação politica}

Esta seção procura articular dois campos de pesquisa que têm evoluído de modo paralelo e indicar as hipóteses de trabalho deste estudo. $\mathrm{O}$ primeiro deles centra sua atenção sobre as transformaçóes tecnológicas dos meios de comunicação de massa e sua repercussão na formação de audiências heterogêneas quanto a seus repertórios midiáticos (BRANDTZÆG, 2010; HASEBRINK e DOMEYER, 2012; CARPENTIER, SCHRODER e HALLET, 2014; HASEBRINK et al., 2015; HELLES et al., 2015). O segundo campo dirige seu interesse aos efeitos dessa reconfiguração midiática sobre diferentes níveis de informação política (DELLI CARPINI e KEETER, 1996; PRIOR, 2007; AALBERG et al., 2010; ELENBAAS et al., 2014).

Náo é original a experiência das sociedades ocidentais com um ciclo de transformação tecnológica em seus sistemas midiáticos. Os jornais impressos, hegemônicos no século XIX, enfrentaram-se ao rádio, ao cinema, à TV e à internet e, até aqui, adaptaram-se e sobreviveram, como argumenta Russell Neuman (2010), que chama a atenção para a capacidade das mídias de se adaptar e conviver com o novó ${ }^{4}$. A percepção de que o uso dos meios de comunicação é socialmente construído opóese ao determinismo tecnológico e deixa abertos, portanto, os contornos do cenário midiático que está em reconfiguração neste momento.

A perspectiva histórica permite relativizar uma certa visão fetichista, que cotidianamente sobrevaloriza as novas tecnologias devido à sua mais recente introdução e aparente ubiquidade (CARPENTIER, SCHRODER e HALLET, 2014). As transformaçóes recentes também contemplam estabilidade (HASEBRINK et al., 2015), ainda que esta seja menos percebida. O próprio esforço das corporaçóes em manter posiçôes dominantes durante a transformação de um contexto midiático

\footnotetext{
${ }^{4}$ Para citar outro exemplo, também o rádio, que a partir dos anos 1940 foi perdendo seu lugar na sala de estar, tratou de encontrar outros espaços, nos quartos, na cozinha, nos carros e, mais recentemente, nos smartphones.
} 
(GOMES, 2005b) é mais uma razão para que exista certa estabilidade, adaptação e sobrevivência.

O que há de indiscutivelmente novo no atual contexto é a inédita multiplicação de mídias, plataformas e conteúdos, que tem estimulado maior fragmentação e individualização das audiências (PRIOR, 2007; CARPENTIER, SCHRODER e HALLET, 2014; HELLES et al., 2015). Por um lado, a internet e a miríade de equipamentos que se conectam a ela tem reduzido custos de produção e distribuição de conteúdo: aumento e diferenciação da oferta favorecem a fragmentação e a individualização da demanda ${ }^{5}$. Por outro, a diversidade crescente na exposição à mídia não é decorrente apenas de variaçóes conjunturais na seleção de veículos ou programas. Novela hoje e futebol amanhã. Origina-se numa diferença estrutural, decorrente da exposição a diversos "repertórios midiáticos" (HASEBRINK e DOMEYER, 2012), que oferecem experiências essencialmente mais distintas que no passado ${ }^{6}$. Hasebrink et al. (2015, p. 439) indicam o surgimento de uma audiência hedonista, muito mais exposta a um conteúdo demandado (pull media) que a outro oferecido (push media).

Crescentes têm sido, até aqui, os esforços por classificar os indivíduos com relação ao uso dos diferentes meios de comunicação, utilizando em grande medida surveys como referencial empírico. Jensen e Helles (2014 apud HASEBRINK et al., 2015) identificam três tipos de usuários na Dinamarca: tradicionalistas (usuários das "velhas" mídias), majoritários (que combinam "velhas" e "novas" mídias) e pluralistas (um grupo menor em que predominam as "novas" mídias). Em Flandres e na Alemanha, Hasebrink et al. (2015) distinguem audiências com base nas funçôes da mídia para os indivíduos e em sua orientação com respeito a interesses culturais e de lazer.

Especificamente sobre a internet, diversos trabalhos têm se dedicado a classificar usuários e até o consumo online (BARNES et al., 2007). Uma revisão de 22 estudos recentes nesse âmbito mostrou que há marcado desentendimento entre os autores sobre as dimensóes relevantes de análise e os tipos daí resultantes (BRANDTZÆG, 2010). Com maior frequência, utilizam-se como dimensôes de

\footnotetext{
5 Portanto, em lugar de uma "audiência" - mais típica do período hegemônico da TV aberta com reduzida competição -, talvez faça mais sentido falar atualmente em "audiências".

6 A definiçáo do conceito de "repertórios midiáticos" utilizada pelos autores incorpora elementos quantitativos (como frequência e intensidade de uso de diferentes mídias) e qualitativos (como a função e o significado do uso da mídia no dia-a-dia dos indivíduos). Ainda que o presente artigo esteja ancorado apenas em dados quantitativos sobre uso da mídia, optou-se pela utilizaçáo do conceito devido à sua pertinência com o objetivo conceitual da pesquisa.
} 
classificação a variedade de uso de meios, sua frequência de uso e o conteúdo preferido ${ }^{7}$.

Com base na literatura acima indicada e no estágio de adesão do Brasil às novas tecnologias, nossa expectativa é que o cenário brasileiro seja marcado pela existência de diferentes repertórios midiáticos nos quais a televisão ainda predomine [H1.1] e que o uso da internet seja mediado por variáveis sociodemográficas. Mais especificamente, este artigo sugere que repertórios midiáticos que incluem a internet estarão mais associados a: [H1.2] pessoas jovens, com menores barreiras cognitivas no uso do novo meio; [H1.3] pessoas mais ricas, com menores limitações para aquisição de equipamentos necessários ao uso da internet; [H1.4] pessoas mais escolarizadas, com maior treinamento e estímulo social para utilizarem o novo meio; [H1.5] pessoas economicamente ativas, que contam com o espaço laboral como oportunidade adicional de uso da internet; [H1.6] pessoas que moram em capitais ou periferias de regiōes metropolitanas, com melhor infraestrutura de telecomunicaçóes e maior oferta de serviços se comparado com o interior do país; e [H1.7] pessoas que moram em regióes economicamente mais desenvolvidas, onde também espera-se que haja maior oferta de serviços.

No segundo campo de estudo, essa reconfiguração midiática decorrente das transformaçóes tecnológicas, notadamente da incorporação da internet e seus equipamentos, tem permitido a renovação do interesse de pesquisa sobre as relaçôes entre a exposição à mídia e os níveis de informação política dos cidadãos. Em perspectiva mais pessimista, Prior (2007) argumenta que a possibilidade de escolha de conteúdo na internet tende a afastar os cidadãos da política, reduzindo níveis de informação e participação. Em vez de reduzir desigualdades no campo político, a internet poderia aprofundá-las.

A literatura recente sobre informação política assenta-se em grande parte sobre o modelo desenvolvido por Delli Carpini e Keeter (1996). Os autores indicam três fatores determinantes do nível de informação política de cada cidadão: oportunidade, motivaçáo e capacidade. A oportunidade descreve os contextos social e midiático que oferecem maior ou menor quantidade de informação disponível (ELENBAAS et al., 2014). A motivação tem caráter individual, psicológico, e dá conta da curiosidade e satisfação individual no mero consumo de informação política. Finalmente, a capacidade cognitiva dos indivíduos refere-se às tarefas de compreensão e incorporação de nova informação ao conhecimento já adquirido. As transformaçôes

\footnotetext{
${ }^{7}$ Variedade de uso está presente em 19 dos 22 estudos analisados pelo autor, seguido por frequência de uso e conteúdo preferido, que aparecem em 12 estudos (BRANDTZÆG, 2010).
} 
midiáticas atuam, sobretudo, na ampliação das oportunidades de aquisição de informação política e na maior liberdade para a seleção de conteúdos segundo motivaçôes individuais.

A literatura revista acima sugere que os indivíduos que tenham a internet como um componente relevante de seu repertório midiático tenderão a ter menos informação política, em decorrência da opção por conteúdos alternativos, como o entretenimento (PRIOR, 2007). Ou seja, [H2] repertórios midiáticos mais dependentes da internet manifestarão menor nível de informação política.

\section{Padrões de uso dos meios de comunicação no Brasil}

O referencial empírico deste estudo é a Pesquisa Brasileira de Mídia (PBM) ${ }^{8}$. Em sua edição de 2015, três questôes contemplam dimensôes consensuais na literatura sobre padróes de uso dos meios de comunicação: (a) exposição aos diferentes meios de comunicação; (b) frequência de exposição em dias por semana e (c) intensidade de uso dos meios em horas diárias. A Figura 2 abaixo traz os principais descritivos das três questóes para os cinco principais meios de comunicação de massa: $\mathrm{TV}$, rádio, internet, jornais impressos e revistas impressas.

\footnotetext{
8 Survey realizado pelo Ibope Inteligência sob encomenda da Secretaria de Comunicação Social da Presidência da República (Secom). A amostra nacional é elaborada por meio da aplicação de um fator de ponderação sobre amostras representativas das 27 Unidades da Federação. O estudo contempla 18.312 entrevistas domiciliares feitas a indivíduos com idade igual ou superior a 16 anos. Os dados em nível nacional têm margem de erro de 1 ponto percentual para intervalo de confiança de 95\%.
} 
Figura 1 - Exposição, frequência e intensidade de uso dos cinco principais meios de comunicação de massa no Brasil

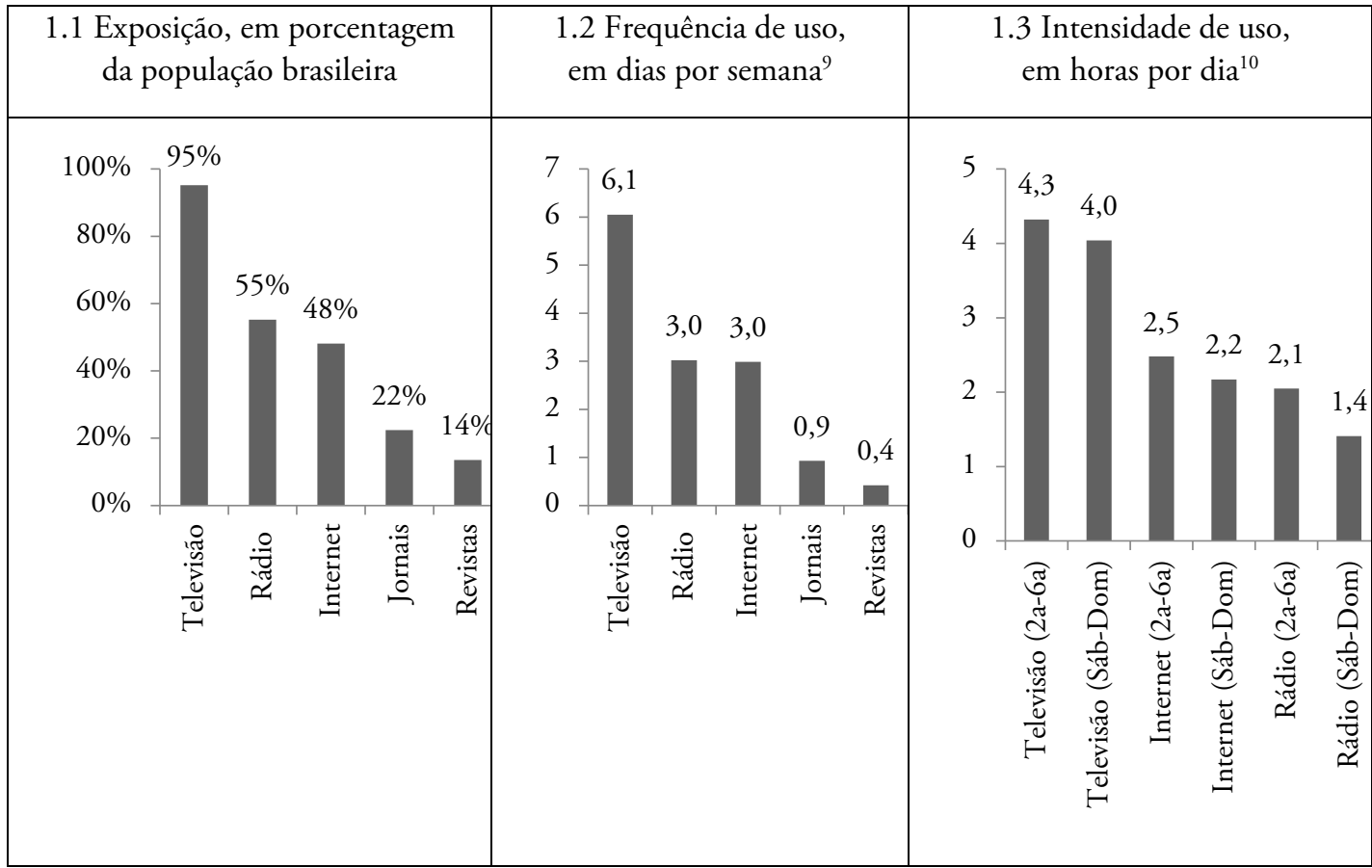

$\mathrm{N}=18.312$

Fonte: Elaboração dos autores com base na Pesquisa Brasileira de Mídia 2015 (BRASIL, 2014).

Os dados mostram um sistema plural. A TV aberta ainda é o meio de comunicação praticamente universal no país, presente no cotidiano da quase totalidade dos brasileiros, com frequência de uso (média de 6 dias por semana) e intensidade de exposição (média superior a 4 horas diárias) superior aos demais meios $^{11}$. Em segundo plano, o rádio e a internet são usados por praticamente metade

\footnotetext{
${ }^{9}$ Os mesmos dados calculados apenas para usuários de cada um dos meios mostram que as frequências de uso, em dias por semana, são de 6,3 para televisão; 5,4 para rádio; 6,2 para internet; 4,1 para jornais impressos e 3,1 para revistas impressas.

${ }^{10}$ Analisando-se somente os usuários de cada um dos meios, observa-se que a intensidade de uso da TV é de 4,5 e 4,2 horas durante a semana e nos finais de semana, respectivamente. Para o Rádio, a intensidade é de 3,7 e 2,6 horas nos dias de semana e nos finais de semana. Já para a internet, a intensidade de uso de seus usuários é de 5,1 e 4,5 horas durante a semana e nos finais de semana, respectivamente.

${ }^{11}$ Os dados descritivos de exposição, frequência e intensidade de uso foram calculados para toda a amostra de 18.312. Náo são apresentados aqui os dados de frequência e intensidade de uso apenas de usuários dos meios para permitir a comparação destes valores com os resultados da análise de cluster
} 
da população nacional. A frequência de uso desses dois meios também é semelhante (com média nacional de 3 dias por semana), sendo maior a intensidade de exposição à internet que ao rádio. Com menor presença, jornais e revistas impressos chegam respectivamente a $22 \%$ e $14 \%$ dos entrevistados. A frequência média de uso dos jornais é de quase um dia por semana e a das revistas é ainda menor.

Os esforços científicos recentes em compreender as transformaçóes tecnológicas no campo da comunicação e seus impactos sobre as audiências acentuaram a importância da pesquisa descritiva, por seu papel organizador e renovador do conhecimento (BABBIE, 1999; GRIMALDI e ENGEL, 2007). Um dos exercícios científicos mais tradicionais nesse âmbito descritivo é a classificação de indivíduos em grupos por critérios de semelhança (BAILEY, 1994), formando conjuntos homogêneos internamente (within group) e heterogêneos externamente (between-group). Seguindo o exemplo de outros estudos que descrevem hábitos de uso da mídia, este trabalho adota uma taxonomia numérica (BAILEY, 1994) baseada na análise de clusters (JAIN et al., 1999).

Dentre os métodos de aplicação da análise de clusters, os dois mais utilizados são os hierárquicos e os não hierárquicos. A principal diferença entre eles consiste na forma como é definido o número de grupos a partir dos dados. Enquanto no primeiro a quantidade de grupos é formada a partir da exploração dos dados, no segundo é necessário que o número de grupos seja especificado pelo pesquisador, a partir de critérios teóricos ou conceituais.

O método hierárquico parte do pressuposto de que todos os indivíduos que compóem a base de dados são diferentes entre si, de modo que cada indivíduo é caracterizado como uma classe diferente. Em seguida, o agrupamento em classes procede por etapas, por meio de sucessivas fusóes de grupos (ou indivíduos) que compartilham características semelhantes.

Já no método não hierárquico, o número $k$ de grupos é especificado pelo pesquisador. Portanto, esse método tem como objetivo encontrar diretamente uma partição de $n$ elementos em $k$ grupos, de modo que a partição satisfaça dois requisitos básicos: semelhança interna e separação dos clusters formados (ou seja, homogeneidade interna e heterogeneidade externa). Há, em cada cluster, um ponto que é a principal referência para que outros pontos semelhantes se unam a ele. Após a comparação do indivíduo a todos os clusters pré-definidos, ele é atribuído ao cluster com o qual tenha maior grau de similaridade. A grande vantagem do método não

apresentada a seguir. Para evitar a perda de casos, a análise atribuiu valor zero à frequência e intensidade de uso daqueles indivíduos que não utilizam determinado meio. 
hierárquico é que ele pode realocar um indivíduo em diferentes clusters ao longo das interaçóes, de modo a que esteja classificado no grupo mais parecido com ele ao final do processo. Por esses motivos, neste estudo adotou-se a técnica não hierárquica conhecida como $k$-médias, que é a mais simples e difundida técnica estatística de formação de agrupamentos ${ }^{12}$.

A escolha pelo método não-hierárquico, ao invés de um método hierárquico para desenvolver o objetivo deste artigo foi primordialmente devido à característica do plano amostral da PBM. Como as amostras são representativas das Unidades da Federação e não do Brasil, a análise dos dados nacionais depende da aplicação de um fator de ponderaçáo que corrige o peso das 27 amostras, cujo $n$ varia entre $504^{13} \mathrm{e}$ $1876^{14}$. Como o software utilizado (SPSS versão 21) não permite a aplicação de um peso durante a utilização de métodos hierárquicos, optou-se pela utilização de método não hierárquico de k-médias, assegurando a proporcionalidade do peso de cada UF na análise.

Para a utilização do método k-médias de clusterização $^{15}$ de indivíduos, a etapa de seleção das variáveis é a mais fundamental, uma vez que são definidas as variáveis referências no agrupamento dos dados ${ }^{16}$. Desse modo, com o objetivo de compreender os vários padróes de uso dos meios de comunicação pela população brasileira, foram selecionadas onze variáveis, que por questóes didáticas são separadas em dois grupos.

$\mathrm{O}$ primeiro grupo diz respeito à frequência de uso dos meios de comunicação e está composto por cinco variáveis que mediram quantos dias por semana o entrevistado disse utilizar cada um dos meios de comunicação: televisão, rádio, internet, jornais e revistas. As respostas variaram entre 0 e 7 dias.

\footnotetext{
${ }^{12}$ Pelo uso desta técnica, o ponto de referência de cada cluster é definido como seu ponto central. A partir desse ponto central referencial, cada elemento amostral é alocado aos clusters cuja centróide esteja mais próximo do vetor de valores observados para o respectivo elemento. Trata-se, portanto, de uma técnica de associação, em que os indivíduos agrupam-se conforme suas características se aproximam do ponto central referencial do cluster pré-definido. Portanto, a técnica k-médias de agrupamento de dados é feita eminentemente de forma ad hoc, a partir da pré-definição da quantidade de grupos.

${ }^{13}$ Roraima, Acre, Rondônia, Amapá, Tocantins, Alagoas, Sergipe, Mato Grosso do Sul e Distrito Federal.

${ }^{14}$ São Paulo.

${ }^{15}$ Neste texto, adotamos o neologismo técnico.

${ }^{16}$ De acordo com Jain et al. (1999) a seleção das variáveis deve ser a que melhor descreve diferentes grupos de observaçôes e que elas façam sentido em relação às características as quais se pretendem usar como referência para agrupar as observaçóes.
} 
Já o segundo grupo de variáveis incluídas na clusterização trata da intensidade de uso dos três principais meios (TV, rádio e internet) em dois períodos em geral distintos do cotidiano brasileiro (o período laboral de segunda à sexta-feira e o fim de semana) ${ }^{17}$. A intensidade de uso dos meios impressos foi excluída da análise por dois motivos. O primeiro, de ordem prática, justifica-se pela ausência de pergunta específica para medir a intensidade de uso das revistas no instrumento de coleta da pesquisa. Já a intensidade de uso dos jornais foi excluída da clusterização, uma vez que se considerou que a variável não é adequada para descrever a forma pela qual os indivíduos interagem com o meio, pois a intensidade está medida em horas e é comum que o uso dos jornais diários se dê em minutos ${ }^{18}$.

Após a simulação com diferentes números de clusters, entre 2 e 24, optou-se pela fixação de seis grupos na análise. Dois critérios foram determinantes na escolha. O primeiro decorrente da intenção de descrever padrốes de uso dos meios de comunicação. Padrões são, por definição, observáveis com frequência. Descartamos, portanto, as soluçóes de classificação que geraram grupos muito inferiores a 10\% dos casos $^{19}$. O segundo critério foi teoricamente orientado e buscava descrever clusters com suficiente variação quanto à composição do repertório midiático e à intensidade de uso. A solução com cinco clusters eliminava um grupo com uso frequente de TV, rádio e internet, por exemplo. Soluçôes com números menores de grupo reduziam ainda mais essa variação.

Os seis padrôes de uso dos meios de comunicação no Brasil são apresentados na Tabela 1. Todos eles, como pode-se observar, revelam uso frequente da TV, reforçando a expectativa da hipótese [H1.1] de que o sistema midiático brasileiro ainda está centrado nesse meio de comunicação. O número total de casos cai de 18.312 a 17.884 (98\% do total) porque a análise desconsidera casos com dados perdidos. O resultado apresenta dois grupos maiores, dois grupos de tamanho médio e dois grupos de tamanho menor.

\footnotetext{
${ }^{17}$ Foram excluídos da amostra os indivíduos que declararam intensidade de uso maior do que vinte horas diárias para qualquer um dos meios, ainda que sua manutençáo alterasse pouco os resultados substantivos deste estudo.

${ }^{18} \mathrm{O}$ Anexo I traz a descrição das variáveis utilizadas.

${ }^{19}$ Soluçóes com sete clusters ou mais produziam grupos com $6 \%$ dos casos ou menos.
} 
Tabela 1 - Resultado da análise de cluster para 6 médias

\begin{tabular}{l|c|c|c|c|c|c}
\hline & $\begin{array}{c}\text { Cluster } \\
\mathbf{1}\end{array}$ & $\begin{array}{c}\text { Cluster } \\
\mathbf{2}\end{array}$ & $\begin{array}{c}\text { Cluster } \\
\mathbf{3}\end{array}$ & $\begin{array}{c}\text { Cluster } \\
\mathbf{4}\end{array}$ & $\begin{array}{c}\text { Cluster } \\
\mathbf{5}\end{array}$ & $\begin{array}{c}\text { Cluster } \\
\mathbf{6}\end{array}$ \\
\hline Frequência de uso de TV & 5,9 & 6,1 & 5,6 & 6,1 & 6,8 & 5,8 \\
\hline Frequência de uso de Rádio & 0,6 & 6,5 & 0,4 & 6,0 & 2,2 & 1,9 \\
\hline $\begin{array}{l}\text { Frequência de uso de } \\
\text { jornais }\end{array}$ & 0,4 & 0,7 & 0,9 & 2,1 & 0,5 & 1,0 \\
\hline $\begin{array}{l}\text { Frequência de uso de } \\
\text { revistas }\end{array}$ & 0,1 & 0,2 & 0,4 & 1,2 & 0,1 & 0,5 \\
\hline $\begin{array}{l}\text { Frequência de uso de } \\
\text { internet }\end{array}$ & 0,2 & 0,1 & 6,6 & 6,5 & 0,7 & 6,8 \\
\hline $\begin{array}{l}\text { Intensidade de uso de TV } \\
\text { (durante a semana) }\end{array}$ & 3,2 & 4,0 & 3,2 & 3,9 & 9,1 & 5,2 \\
\hline $\begin{array}{l}\text { Intensidade de uso de TV } \\
\text { (finais de semana) }\end{array}$ & 2,5 & 3,8 & 2,7 & 3,8 & 9,4 & 5,2 \\
\hline $\begin{array}{l}\text { Intensidade de uso de Rádio } \\
\text { (durante a semana) }\end{array}$ & 0,3 & 4,6 & 0,3 & 3,6 & 1,5 & 1,6 \\
\hline $\begin{array}{l}\text { Intensidade de uso de Rádio } \\
\text { (finais de semana) }\end{array}$ & 0,1 & 3,4 & 0,1 & 2,6 & 1,0 & 0,9 \\
\hline $\begin{array}{l}\text { Intensidade de uso de } \\
\text { Internet (durante a semana) }\end{array}$ & 0,1 & 0,1 & 3,8 & 4,0 & 0,3 & 11,5 \\
\hline $\begin{array}{l}\text { Intensidade de uso de } \\
\text { Internet (finais de semana) }\end{array}$ & 0,0 & 0,0 & 3,0 & 3,4 & 0,2 & 11,0 \\
\hline \begin{tabular}{l} 
Tamanho \\
\hline
\end{tabular} & $25 \%$ & $22 \%$ & $18 \%$ & $15 \%$ & $11 \%$ & $9 \%$ \\
\hline
\end{tabular}

Fonte: Elaboraçáo própria.

O cluster 1 é composto por $25 \%$ dos entrevistados. Caracteriza-se pelo uso exclusivo da televisão, com frequência próxima a seis dias por semana e intensidade moderada, de 3,3 horas durante a semana e de 2,5 horas nos finais de semana, por isso foi denominado "Só TV". É formado majoritariamente por habitantes de cidades do interior das regióes Norte e Nordeste, casados, muito pobres e com baixa escolaridade e, em geral, mais velhos.

O cluster 2 está composto por $22 \%$ dos indivíduos e revela uso combinado de "TV e rádio". A frequência de uso de cada um dos meios é próxima a seis dias por semana, com intensidade semelhante à média nacional. Neste grupo predominam indivíduos casados de baixa escolaridade e adultos, mas moradores de cidades do interior da regiáo Sul, onde a economia se desenvolveu o suficiente para manter importante oferta de estaçóes de rádio em diferentes localidades de cada um dos três estados.

O cluster 3, com 18\% dos entrevistados, define-se pelo uso moderado de "TV e internet", com discreto predomínio deste último. O grupo é formado por indivíduos jovens, solteiros, com renda e escolaridade mais altas, empregados com 
carteira assinada ou funcionários públicos, e moradores de metrópoles do Sudeste e Centro-Oeste.

O quarto cluster tem o repertório mais diversificado de meios de comunicação, com uso praticamente diário de TV, rádio e internet ("TRI"), além de leitura de jornais e revistas com frequência significativamente acima do observado sobre o total da amostra. Estão mais representados, neste grupo, brasileiros na faixa etária dos 18 aos 34 anos, moradores das periferias metropolitanas, mas também empresários e profissionais liberais. Trata-se de um grupo bastante heterogêneo em termos sociodemográficos.

Assim como o grupo "só TV", o cluster 5 (composto por 11\% da amostra) contém indivíduos que possuem uso praticamente exclusivo de televisão. Entretanto, a principal diferença entre eles está na intensidade de uso, que se triplica. Este grupo, denominado "TV+", é formado majoritariamente por mulheres, com maior presença de indivíduos com baixa escolaridade, idade igual ou superior a 55 anos, moradores do Sudeste e inativos ou que se dedicam a atividades domésticas. Em geral, portanto, pessoas com tempo mais disponível para o uso da TV ou que a utilizam como companhia, caso passem boa parte do dia sozinhas.

Por último, o grupo 6 ( $9 \%$ dos indivíduos) é composto pelos entrevistados que compartilham principalmente o uso de televisão e internet, assim como o grupo 3. Entretanto, o quase se quadruplica aqui é a exposição diária à internet, superior a 11 horas em média. O grupo, denominado "TV e internet+" é formado por jovens, com sobrerrepresentação da faixa até 24 anos, de alta escolaridade, solteiros, brancos e moradores do Sudeste.

Com o objetivo de aprofundar a descrição sociodemográfica de cada um dos grupos, realizou-se uma regressáo logística multinominal com o objetivo de identificar que características estão mais associadas a cada cluster. A análise manteve como grupo de referência o maior deles - "só TV" - e estimou a influência de variáveis sociodemográficas sobre a probabilidade de pertencer a um dos demais cinco clusters. O resultado está na Tabela 2. 
24 | Wladimir G. Gramacho e André Jácomo

Tabela 2 - Descrição dos clusters a partir de variáveis sociodemográficas (odds-ratio)

\begin{tabular}{|c|c|c|c|c|c|}
\hline & $\begin{array}{c}\text { Cluster } 2 \\
\text { (TV e } \\
\text { Rádio) }\end{array}$ & $\begin{array}{c}\text { Cluster } 3 \\
\text { (TV e } \\
\text { Web) }\end{array}$ & $\begin{array}{c}\text { Cluster } 4 \\
\text { (TRI) }\end{array}$ & $\begin{array}{c}\text { Cluster } 5 \\
(\mathrm{TV}+)\end{array}$ & $\begin{array}{c}\text { Cluster } 6 \\
\text { (TV e } \\
\text { Web+) }\end{array}$ \\
\hline \multicolumn{6}{|l|}{ Gênero $^{20}$} \\
\hline Masculino & $1,126^{*}$ & ,880* & ,944 & ,740* & ,887 \\
\hline \multicolumn{6}{|l|}{ Idade $^{21}$} \\
\hline Idade & 1,003 & ,931* & ,947* & ,997 & ,907* \\
\hline \multicolumn{6}{|l|}{ Escolaridade $^{22}$} \\
\hline $5^{\mathrm{a}}$ a $8^{\mathrm{a}}$ série & 1,032 & $2,652^{*}$ & $2,233^{*}$ & 1,052 & $3,005^{*}$ \\
\hline Ensino Médio & ,846* & $6,738^{*}$ & $5,151^{*}$ & ,982 & $8,346^{*}$ \\
\hline Ensino Superior &, $715^{*}$ & $21,089^{*}$ & $12,641^{*}$ & ,783 & $24,133^{*}$ \\
\hline \multicolumn{6}{|l|}{ Renda Familiar ${ }^{23}$} \\
\hline 1 a 2 SM & 1,095 & 1,095 & $1,385^{*}$ & $1,205^{*}$ & 1,085 \\
\hline 2 a 5 SM & $1,262^{*}$ & $1,989^{*}$ & $2,345^{*}$ & $1,409^{*}$ & $1,889^{*}$ \\
\hline 5 a 10 SM & $1,297^{*}$ & $3,124^{*}$ & $3,985^{*}$ & 1,255 & $3,217^{*}$ \\
\hline Mais de $10 \mathrm{SM}$ & 1,438 & $5,477^{*}$ & $8,333^{*}$ & ,908 & $7,491^{*}$ \\
\hline \multicolumn{6}{|c|}{ Condição do Município ${ }^{24}$} \\
\hline Capital & 1,019 & $1,722^{*}$ & $1,481^{*}$ & $1,372^{*}$ & $1,750^{*}$ \\
\hline Periferia & $1,212^{*}$ & $1,274^{*}$ & $1,816^{*}$ & 1,094 & $1,477^{*}$ \\
\hline \multicolumn{6}{|l|}{ Regiāo $^{25}$} \\
\hline Nordeste & $1,553^{*}$ &, 897 & $1,745^{*}$ & $1,646^{*}$ & $1,972^{*}$ \\
\hline Sudeste & $1,656^{*}$ & $1,340^{*}$ & $2,295^{*}$ & $2,585^{*}$ & $3,005^{*}$ \\
\hline Sul & $3,732^{*}$ & 1,257 & $4,472^{*}$ & $3,028^{*}$ & $3,016^{*}$ \\
\hline Centro-Oeste & $1,413^{*}$ & $1,472^{*}$ & $2,091^{*}$ & $1,702^{*}$ & $2,929^{*}$ \\
\hline \multicolumn{6}{|c|}{ Ramo de Atividade ${ }^{26}$} \\
\hline Ativos & 994 & $1,139^{*}$ & $1,160^{*}$ &, $516^{*}$ & 991 \\
\hline \multicolumn{6}{|l|}{$\operatorname{Raça}^{27}$} \\
\hline Negros & 1,036 & ,788* & ,923 & ,931 &, $668^{*}$ \\
\hline Pardos & ,987 &, $774^{*}$ & ,798* & 909 &, $628^{*}$ \\
\hline Outros & ,751 & ,764 & ,629* &, $555^{*}$ &, $524^{*}$ \\
\hline
\end{tabular}

${ }^{*} \mathrm{p}<0.05$

Fonte: Elaboração própria.

${ }^{20}$ Categoria de referência: mulheres.

${ }^{21}$ Variável contínua.

${ }^{22}$ Categoria de referência: até $4^{\circ}$ série.

${ }^{23}$ Categoria de referencia: Até 1 salário mínimo.

${ }^{24}$ Categoria de referência: interior.

${ }^{25}$ Categoria de referência: Norte.

${ }^{26}$ Categoria de referência: Inativos.

${ }^{27}$ Categoria de referência: brancos. 
Tomando como referência o grupo que só assiste TV, a presença de homens só é maior no cluster que inclui rádio, meio por natureza ligado à mobilidade, seja por estar presente no carro ou em outros dispositivos móveis. A menor presença do homem em casa, onde costuma estar a TV ou computadores, pode ser uma explicação para esse resultado. Quanto à idade, o número maior de anos de vida reduz as chances de que os indivíduos participem de clusters que contemplam o uso da internet, num resultado homogêneo e esperado. $O$ mesmo se dá com renda e escolaridade, em que os resultados foram bastante estáveis. A maior renda e escolaridade, corresponde maior probabilidade de pertencimento a clusters que usam a internet. Entre as duas variáveis, entretanto, é notável o efeito de atingir o nível superior de estudos, que tornam muito mais provável o pertencimento aos clusters predominantemente digitais (3, de modo discreto, e 6, de modo acentuado).

A vida na capital também oferece maiores oportunidades de uso da internet, pela disponibilidade logística e comercial. Em geral, quanto mais distante do interior, menos provável é o pertencimento ao grupo que só assiste TV. O padrão de uso dos meios de comunicação no Sul é o que mais se distingue do Norte (categoria de referência na análise), seguido pelo Sudeste. Por outro lado, ser economicamente ativo reduz praticamente à metade as chances de pertencer ao grupo que assiste muita TV (cluster 5). Finalmente, em consonância com o cenário de desigualdade racial da sociedade brasileira, declarar-se negro ou pardo esteve associado com menores probabilidades de pertencer a clusters com repertórios midiáticos mais diversificados, sendo especialmente notável a redução nas chances de estar no sexto grupo, que apresenta uso intensivo de internet. Esse resultado, vale registrar, deu-se em modelo que incorpora em outras variáveis os efeitos de renda, educação e condição do município (i.e. capital, periferia e interior).

Em geral, as expectativas sobre os determinantes de uso de repertórios midiáticos que incluem a internet foram confirmadas, mais especificamente quanto à maior associação de uso desse meio digital e a população mais jovem [H1.2], mais rica [H1.3], mais escolarizada [H1.4], economicamente ativa [H1.5], moradora de áreas metropolitanas [H1.6] e de regiôes geográficas mais ricas [H1.7].

\section{Repertórios midiáticos e informação politica}

A PBM-2015 também contemplou uma bateria com quatro questóes que permitem construir um índice de informação política. As questôes solicitavam ao entrevistado que indicasse: (i) a área de maior gasto do orçamento federal em 2013 (entre Forças Armadas, Previdência Social e estradas); (ii) o responsável pelo pagamento de aposentadorias a trabalhadores com carteira assinada (Prefeitura, 
Governo do Estado ou Governo Federal); (iii) o responsável pela representação do Brasil na relação com outros países (Prefeito, Governador ou Presidente da República); e (iv) o responsável pelo controle da inflação (governo municipal, estadual ou federal). A soma das respostas corretas gerou um índice com valor 0 para quem errou todas as questóes, 1 para quem acertou uma, e assim sucessivamente até 4 para quem respondeu corretamente todas elas ${ }^{28}$.

O teste do efeito dos repertórios midiáticos sobre o nível de informação política foi realizado a partir de uma análise de regressão ordinal, em que se busca estimar o efeito de cada variável independente sobre a chance de avançar uma unidade no índice de informação política. A principal variável de interesse aqui é o cluster midiático a que pertence o indivíduo. A categoria de referência é o maior grupo, que só assiste a TV, e coeficientes da tabela $(\exp (B))$ mostram o efeito de pertencimento aos demais grupos em comparação com o grupo de referência. Acompanhando estudos anteriores (RENNÓ, 2007), foram introduzidas no modelo variáveis para gênero (dummy que indica o sexo masculino), cor autodeclarada (tendo os que se declaram brancos como referência) e renda familiar (tendo como referência renda até 1 salário mínimo). O modelo incluiu também controles para idade (contínua), escolaridade (tendo como referência indivíduos que estudaram até a $4^{\mathrm{a}}$ série) e localidade de moradia (tendo como referência os que vivem em cidades do interior).

O modelo também contempla a dimensão de interesse por política, ou motivação, que também explicaria diferentes níveis de informação política (DELLI CARPINI e KEETER, 1996; PRIOR, 2007). A PBM-2015 questionou os entrevistados sobre o nível de interesse de cada um deles em notícias sobre o que fazem o Governo Federal, o Governo Estadual e o Governo Municipal. O índice de interesse atribui valor 1 para cada vez que o respondente informou ter "muito interesse" ou "médio interesse" por notícias de cada um desses entes de governo. Os resultados da regressão são apresentados na Tabela 3.

${ }^{28} \mathrm{O}$ teste Alfa de Cronbach do índice é de 0,605. 
Tabela 3 - Regressão logística ordinal: Índice de Informação Política

\begin{tabular}{|c|c|}
\hline Variável & Odds ratio \\
\hline \multicolumn{2}{|l|}{ Limites } \\
\hline $\mathrm{IIP}=0$ & $0,42^{* * *}$ \\
\hline $\mathrm{IIP}=1$ & 1,03 \\
\hline $\mathrm{IIP}=2$ & $2,73^{* * *}$ \\
\hline $\mathrm{IIP}=3$ & $27,70^{* * *}$ \\
\hline Homem & $1,41^{* * *}$ \\
\hline Idade & $1,01^{* * *}$ \\
\hline \multicolumn{2}{|l|}{ Escolaridade (ref: até 4a série) } \\
\hline 5a-8a série & $1,53^{* * *}$ \\
\hline Ensino médio & $1,95^{* * *}$ \\
\hline Ensino superior & $3,05^{* * *}$ \\
\hline \multicolumn{2}{|c|}{ Renda Familiar (ref: até 1 salário mínimo) } \\
\hline 1 a 2 salários mínimos & $1,25^{* * *}$ \\
\hline 2 a 5 salários mínimos & $1,58^{* * *}$ \\
\hline 5 a 10 salários mínimos & $1,72^{* * *}$ \\
\hline Mais de 10 salários mínimos & $1,53^{* * *}$ \\
\hline \multicolumn{2}{|l|}{ Localidade (ref: interior) } \\
\hline Capital & 0,96 \\
\hline Periferia & $0,66^{* * *}$ \\
\hline \multicolumn{2}{|l|}{ Cor da pele (ref: branco) } \\
\hline Negro & $0,70^{* * *}$ \\
\hline Pardo & 1,02 \\
\hline Outras (inclui os que não declararam) & $0,78^{* *}$ \\
\hline Interesse por assuntos do governo & $1,28^{* * *}$ \\
\hline \multicolumn{2}{|l|}{ Cluster midiático (ref: só TV) } \\
\hline TV e Web+ & $1,30^{* * *}$ \\
\hline $\mathrm{TV}+$ & $1,11^{*}$ \\
\hline TRI (TV+Rádio+Internet) & $1,23^{* * *}$ \\
\hline TV e Web & $1,36^{* * *}$ \\
\hline TV e Rádio & $1,09^{*}$ \\
\hline
\end{tabular}

${ }^{*} \mathrm{p}<0.05 ;{ }^{* *} \mathrm{p}<0.01 ;{ }^{* * *} \mathrm{p}<0.001$

Fonte: Elaboração própria.

Os coeficientes $(\exp (B))$ da tabela estáo em geral no sentido descrito pela literatura. Com maior chance de revelar um nível de informaçáo política mais alto estáo homens, indivíduos com maior idade, e com escolaridade e renda familiar mais alta, assim como os que têm maior interesses por informaçôes sobre o que os governos fazem. Por outro lado, moradores de periferia têm menor chance de ter 
maior informação política em comparação com habitantes do interior, assim como negros em comparação com brancos.

O principal interesse na análise, contudo, recai sobre as variáveis que indicam os clusters midiáticos a que pertencem os entrevistados. E, ao contrário do que sugere a hipótese [H2], o uso de internet não está associado a menores níveis de informação política, senão a maiores. Mesmo controlando os efeitos das dimensôes "motivação" (i.e. interesse por informação sobre os governos) e "capacidade" (i.e. escolaridade, utilizada aqui como proxy para competência para compreender e armazenar informaçáo), observa-se um efeito independente dos clusters midiáticos sobre as chances de revelar maior nível de informação política. E os clusters com maiores efeitos, comparados ao grupo que só assiste TV, são justamente os que contemplam a internet: TV e Web; TV e Web+; e TRI (TV, rádio e internet). Os grupos sem internet têm efeito menor e estatisticamente significativo por margem também menor: TV+; e TV e Rádio.

Se por um lado o resultado mostra um efeito consistente, por outro os dados da PBM-2015 não oferecem explicação óbvia para esse efeito. A maior possibilidade de escolha de conteúdo na internet tende a afastar o cidadão não interessado em política desses assuntos. Entretanto, os internautas interessados em política têm na web uma fonte inesgotável de informação, notícia e conhecimento sobre diferentes aspectos da vida política brasileira e internacional. Ou seja, o efeito da internet em aumentar os níveis de informaçáo política dos interessados pode mais que compensar o possível baixo nível de informaçáo daqueles que buscam entretenimento. Fenômeno que náo se pode observar na TV aberta, que oferece a mesma quantidade de informação política para os mais e os menos interessados. Além disso, a experiência no uso da internet implica necessariamente (i) iniciativa do usuário ao selecionar o conteúdo a ser utilizado, (ii) uso de maiores recursos de comunicação que ativam mecanismos cognitivos e reforçam informaçóes veiculadas (i.e. texto, fotografias, infografias, vídeos e áudios), e (iii) maior atenção ao conteúdo, no mínimo para determinar a continuidade ou interrupção da exposição. Estas interpretaçóes dos resultados obtidos neste artigo, contudo, devem ser objeto de novas pesquisas que utilizem instrumentos mais adequados ao esclarecimento dos mecanismos causais que podem vincular o uso da internet a maiores níveis de informação política. 


\section{Conclusões}

As transformaçôes tecnológicas nos sistemas midiáticos de diversos países têm gerado diferentes padrôes de uso dos meios de comunicação de massa. No Brasil, segundo os resultados deste estudo, pode-se dizer que há seis padrốes de uso marcadamente distintos entre si. Três deles têm hábitos offline: os que utilizam "só TV", os que usam muita TV $(\mathrm{TV}+)$ e os que combinam TV e rádio. Outros três padróes incorporam a nova mídia: TV e internet, TV e muita internet (TV e Web+) e o que usa TV, rádio e internet ("TRI"). Há ainda marcadas diferenças sociodemográficas entre eles, o que sugere uma diferenciação também no significado que tem o uso de cada meio entre os diferentes clusters. O papel da TV no grupo $\mathrm{TV}+$, exposto por quase dez horas diárias ao meio, tende a ser muito diferente do papel da TV para o grupo TV e Web+, que se expóe à internet por mais de dez horas diárias. Faz mais sentido, portanto, entender o uso combinado desses diferentes meios como "repertórios midiáticos" (HASEBRINK e DOMEYER, 2012) que oferecem diferentes experiências entre os indivíduos e fontes de informaçáo sobre fatos intangíveis. O único elemento comum entre os clusters identificados é o uso da TV, o que mostra que o sistema brasileiro ainda está centrado nesse meio, padrão não muito diferente do encontrado por Helles et al. (2015) ao estudar os casos europeus. O sistema nacional, portanto, ainda que seja muito mais diversificado e fragmentado que há duas décadas, ainda está - frise-se - centrado na TV.

Se a radiografia da PBM-2015 capta uma fase intermediária de uma transformação em curso, é esperável que, ao longo dos próximos anos, os grupos "só TV", "TV+" e "TV e rádio" tornem-se menores, enquanto que os grupos que já estão expostos à internet cresçam. O corte temporal, portanto, traz a primeira limitação deste estudo. Se por um lado ele revela o atual estado de fragmentaçáo do uso da mídia no Brasil, por outro, sua contribuição é notadamente perene. Estudos futuros, com novos dados, devem se ocupar da evolução desse processo de transformaçáo no uso dos meios de comunicaçáo de massa no País.

A exposição a um repertório midiático que oferece maior autonomia de escolha sobre o conteúdo, entretanto, não parece necessariamente afastar os indivíduos da política ou, mais especificamente, reduzir seu nível de informação política. Ao contrário do que sugere Prior (2007), os resultados da PBM-2015 mostram uma associação entre clusters que combinam maior uso da internet e maiores níveis de informação política. Esse achado não deixa de apoiar expectativas mais otimistas com relação às possibilidades de ampliaçáo do exercício democrático quando for universal o acesso dos cidadãos à internet. Etapa ainda futura da agenda brasileira. Até lá, contudo, outros estudos podem procurar esclarecer os mecanismos 
causais que levam o usuário dessa nova mídia a ter maior informação política num meio com farta disponibilidade de conteúdo de entretenimento e recursos de comunicação interpessoal.

Wladimir G. Gramacho é Professor Adjunto da Faculdade de Comunicação da Universidade de Brasília (UnB) e Doutor em Ciência Política pela Universidade de Salamanca. E-mail: wggramacho@gmail.com.

André Jácomo é Professor Assistente do Centro Universitário do Distrito Federal (UDF) e Mestre em Ciência Política pela UnB. Email: jacomo.andre@gmail.com.

\section{Referências}

AALBERG, Toril et al. Media Systems and the Political Information Environment: A Cross-National Comparison. The International Journal of Press/Politics, v. 15, n. 3, p. 255-271, 2010.

BABBIE, Earl. Métodos de Pesquisas de Survey. Belo Horizonte: Editora UFMG, 1999.

BAILEY, Kenneth. Typologies and taxonomies: an introduction to classification techniques. Thousand Oaks: Sage Publications, 1994.

BARNES, Stuart J. et al. Segmenting cyberspace: a customer typology for the internet. European Journal of Marketing, v. 41, n. 1/2, p. 71 - 93, 2007.

BRANDTZÆG, Petter Bae. Towards a unified Media-User Typology (MUT): A meta-analysis and review of the research literature on media-user typologies. Computers in Human Behavior, v. 26, n. 5 , p. 940-956, set. 2010. Disponível em: <http://doi.org/10.1016/j.chb.2010.02.008>. Acesso em: 17 nov. 2015.

BRASIL. Presidência da República. Secretaria de Comunicação Social. Pesquisa Brasília de Mídia 2015: hábitos de consumo de mídia pela população brasileira. Brasília: Secom, 2014.

CARDOSO, Gustavo. "Sociedades em Transiçāo para a Sociedade em Rede". Em: A Sociedade em Rede: do Conhecimento à Acção Política, Manuel Castells e Gustavo Cardoso (orgs.). Imprensa Nacional: Lisboa. 2005. p 31-64.

CARPENTIER, Nico; SCHRODER, Kim Christian.; HALLET, Lawrie. Audience/Society Transformations. In: CARPENTIER, Nico; SCHRODER, Kim Christian.; HALLET, Lawrie (Eds.). Audience Transformations: Shifting Audience Positions in Late Modernity. New York: Routledge, 2014. p. 1-12.

CASTELLS, Manuel. "A Sociedade em Rede: do Conhecimento à Política". Em: A Sociedade em Rede: do Conhecimento à Acção Política, Manuel Castells e Gustavo Cardoso (orgs.). Imprensa Nacional: Lisboa. 2005. p 17-30. 
DELLI CARPINI, Michael X.; KEETER, Scott. What Americans Know About Politics and Why It Matters. New Haven: Yale University Press, 1996.

DINIZ, Eduardo Henrique; BARBOSA, Alexandre Fernandes; JUNQUEIRA, Alvaro Ribeiro Botelho; PRADO, Otavio. O governo eletrônico no Brasil: perspectiva histórica a partir de um modelo estruturado de análise. Revista de Administração Pública. v. 43, n.1, p. 23-48, 2005a.

ELENBAAS, Matthijs et al. Reconciling Passive and Motivated Learning: The Saturation-Conditional Impact of Media Coverage and Motivation on Political Information. Communication Research, v. 41, n. 4, p. 481-504, 2014.

GOMES, Wilson. A democracia digital e o problema da participação civil na decisão política. Revista Fronteira (UNISINOS), São Leopoldo, v. VIII, n.3, p. 214-222. 2005 b.

GOMES, Wilson. 2005b. Internet e participação política em sociedades democráticas. Revista Famecos, Porto Alegre, n. 27, p. 58-78, ago.

GRIMALDI, David A.; ENGEL, Michael S. Why Descriptive Science Still Matters. BioScience, v. 57, n. 8, p. 646-647, 2007.

HASEBRINK, Uwe et al. Changing Patterns of Media Use Across Cultures: A Challenge for Longitudinal Research. International Journal of Communication, v. 9, p. 435-457, 2015.

HASEBRINK, Uwe; DOMEYER, Hanna. Media repertoires as patterns of behaviour and as meaningful practices: A multimethod approach to media use in converging media environments. Journal of Audience and Reception Studies, v. 9, n. 2, p. 757-779, nov. 2012.

HELLES, Rasmus et al. The Media Landscapes of European Audiences. International Journal of Communication, v. 9, p. 299-319, 2015.

JAIN, Anil K. et al. Data clustering: a review. ACM Computing Surveys, v. 31, n. 3, p. 264-323, 1999.

JENSEN, Klaus Bruhn; HELLES, Rasmus. Danskernes mediebrug 2014: Hverdag og demokrati [Media use in Denmark 2014: Everyday life and democracy]. Copenhagen, Denmark: Kulturstyrelsen, 2014.

LOADER, Brian D. The Governance of Cyberspace: Politics, Technology and Global Restructuring. New York: Routledge. 1997.

MEDEIROS, Paulo Henrique Ramos; GUIMARÁES, Tomás de Aquino. "A Institucionalização do Governo Eletrônico no Brasil". Revista de Administração de Empresas. v. 46, n. 4, p. 66-78, 2006.

NEUMAN, Russell. Theories of Media Evolution. In: NEUMAN, Russell (Ed.). Media, Technology, and Society: Theories of Media Evolution. Michigan: The University of Michigan Press, 2010. p. 121.

PRIOR, Markus. Post-Broadcast Democracy: How Media Choice Increases Inequality in Political Involvement and Polarizes Elections. Cambridge: Cambridge University Press, 2007.

RENNÓ, Lucio R. Desigualdade e informação política: as eleições brasileiras de 2002. Dados, Rio de Janeiro, v. 50, n. 4, p. 721-755, 2007.

UIT. Statistics. 2014. Disponível em: <www.itu.int/en/ITU-D/Statistics/Pages/stat/default.aspx>.. Acesso em: 17 nov. 2015. 
32 | Wladimir G. Gramacho e André Jácomo

Texto recebido em 08 de outubro de 2015. Aprovado em 16 de novembro de 2015. 


\section{Anexos}

Anexo 1 - Variáveis utilizadas na análise de clusters

\begin{tabular}{|c|c|c|c|}
\hline & Meio & Pergunta & Escala \\
\hline \multirow[t]{5}{*}{$\begin{array}{l}\text { Frequência } \\
\text { de Uso }\end{array}$} & TV & $\begin{array}{l}\text { Quantos dias por semana, de segunda a domingo, o(a) } \\
\text { sr(a) assiste TV? }\end{array}$ & 0 a 7 \\
\hline & Rádio & $\begin{array}{l}\text { Quantos dias por semana, de segunda a domingo, o(a) } \\
\text { sr(a) ouve rádio? }\end{array}$ & 0 a 7 \\
\hline & Jornal & $\begin{array}{l}\text { Quantos dias por semana, de segunda a domingo, o(a) } \\
\operatorname{sr}(\mathrm{a}) \text { lê jornais? }\end{array}$ & 0 a 7 \\
\hline & Revista & $\begin{array}{l}\text { Quantos dias por semana, de segunda a domingo, o(a) } \\
\text { sr(a) lê revistas? }\end{array}$ & 0 a 7 \\
\hline & Internet & $\begin{array}{l}\text { Quantos dias por semana, de segunda a domingo, o(a) } \\
\text { sr(a) utiliza a internet? }\end{array}$ & 0 a 7 \\
\hline \multirow{3}{*}{$\begin{array}{l}\text { Intensidade } \\
\text { de uso } \\
\text { durante a } \\
\text { semana }\end{array}$} & TV & $\begin{array}{l}\text { O(a) sr(a) tem costume de ver TV de segunda a sexta- } \\
\text { feira? Quando o (a) sr(a) vê TV de segunda à sexta- } \\
\text { feira, de que hora a que hora costuma ver mais? }\end{array}$ & 0 a 20 \\
\hline & Rádio & $\begin{array}{l}\mathrm{O} \text { (a) sr(a) tem costume de ouvir rádio de segunda a } \\
\text { sexta-feira? Quando o (a) sr(a) ouve rádio de segunda à } \\
\text { sexta-feira, de que hora a que hora costuma ouvir mais }\end{array}$ & 0 a 20 \\
\hline & Internet & $\begin{array}{l}\mathrm{O} \text { (a) sr(a) tem costume de usar internet de segunda a } \\
\text { sexta-feira? De segunda a sexta-feira, de que horas a } \\
\text { que horas o(a) sr(a) costuma usar mais a internet? }\end{array}$ & 0 a 20 \\
\hline \multirow{3}{*}{$\begin{array}{l}\text { Intensidade } \\
\text { de uso nos } \\
\text { finais de } \\
\text { semana }\end{array}$} & TV & $\begin{array}{l}\mathrm{O}(\mathrm{a}) \text { sr(a) tem costume de ver TV no final de semana? } \\
\text { Quando o (a) sr (a) vê TV no final de semana, que } \\
\text { horário costuma ver mais? }\end{array}$ & 0 a 20 \\
\hline & Rádio & $\begin{array}{l}\mathrm{O}(\mathrm{a}) \operatorname{sr}(\mathrm{a}) \text { tem costume de ouvir rádio nos finais de } \\
\text { semana? Quando o (a) sr (a) ouve rádio no final de } \\
\text { semana, que horário costuma ouvir mais? }\end{array}$ & 0 a 20 \\
\hline & Internet & $\begin{array}{l}\mathrm{O}(\mathrm{a}) \mathrm{sr}(\mathrm{a}) \text { tem costume de usar a internet nos finais de } \\
\text { semana? E nos finais de semana, de que horas a que } \\
\text { horas o(a) sr(a) costuma usar mais a internet? }\end{array}$ & 0 a 20 \\
\hline
\end{tabular}

Fonte: Elaboração de autores. 
34 | Wladimir G. Gramacho e André Jácomo

Anexo 2 - Características sociodemográficas dos 6 padróes de uso da mídia no Brasil

\begin{tabular}{|c|c|c|c|}
\hline & Cluster 1 (Só TV) & \multicolumn{2}{|c|}{ Cluster 2 (TV+Rádio) } \\
\hline $\begin{array}{l}\text { Masculino } \\
\text { Feminino }\end{array}$ & \begin{tabular}{|r}
$49 \%$ \\
$51 \%$ \\
\end{tabular} & $\begin{array}{l}\text { Masculino } \\
\text { Feminino }\end{array}$ & \begin{tabular}{|c|c|}
$52 \%$ \\
$48 \%$
\end{tabular} \\
\hline Idade & 47 & Idade & 48 \\
\hline Até 4a série & $44 \%$ & Até 4a série & $46 \%$ \\
\hline $5^{a}$ a $8^{a}$ séric & $25 \%$ & $5^{a}$ a $8^{a}$ scric & $27 \%$ \\
\hline Ensino Médio & $27 \%$ & Ensino Médio & $23 \%$ \\
\hline Fnsino Superior & $5 \%$ & Fnsino Superior & $4 \%$ \\
\hline Até $1 \mathrm{SM}$ & $20 \%$ & Até 1 SM & $18 \%$ \\
\hline De 1 a $2 \mathrm{SM}$ & $39 \%$ & De 1 a 2 SM & $37 \%$ \\
\hline De 2 a $5 \mathrm{SM}$ & $26 \%$ & De 2 a 5 SM & $31 \%$ \\
\hline De 5 a $10 \mathrm{SM}$ & $6 \%$ & De 5 a 10 SM & $7 \%$ \\
\hline Mais de $10 \mathrm{SM}$ & $1 \%$ & Mais de $10 \mathrm{SM}$ & $1 \%$ \\
\hline Capital & $20 \%$ & Capital & $18 \%$ \\
\hline Periferia & $11 \%$ & Periferia & $13 \%$ \\
\hline Interior & $69 \%$ & Interior & $68 \%$ \\
\hline Norte & $11 \%$ & Norte & $6 \%$ \\
\hline Nordeste & $34 \%$ & Nordeste & $29 \%$ \\
\hline Sudeste & $39 \%$ & Sudeste & $38 \%$ \\
\hline Sul & $9 \%$ & Sul & $21 \%$ \\
\hline Centro-Oeste & $7 \%$ & Centro-Oeste & $5 \%$ \\
\hline Inativos & $40 \%$ & Inativos & $39 \%$ \\
\hline Arivos & $60 \%$ & Arivos & $6 ! \%$ \\
\hline
\end{tabular}


Padrões de uso dos meios de comunicação no Brasil | 35

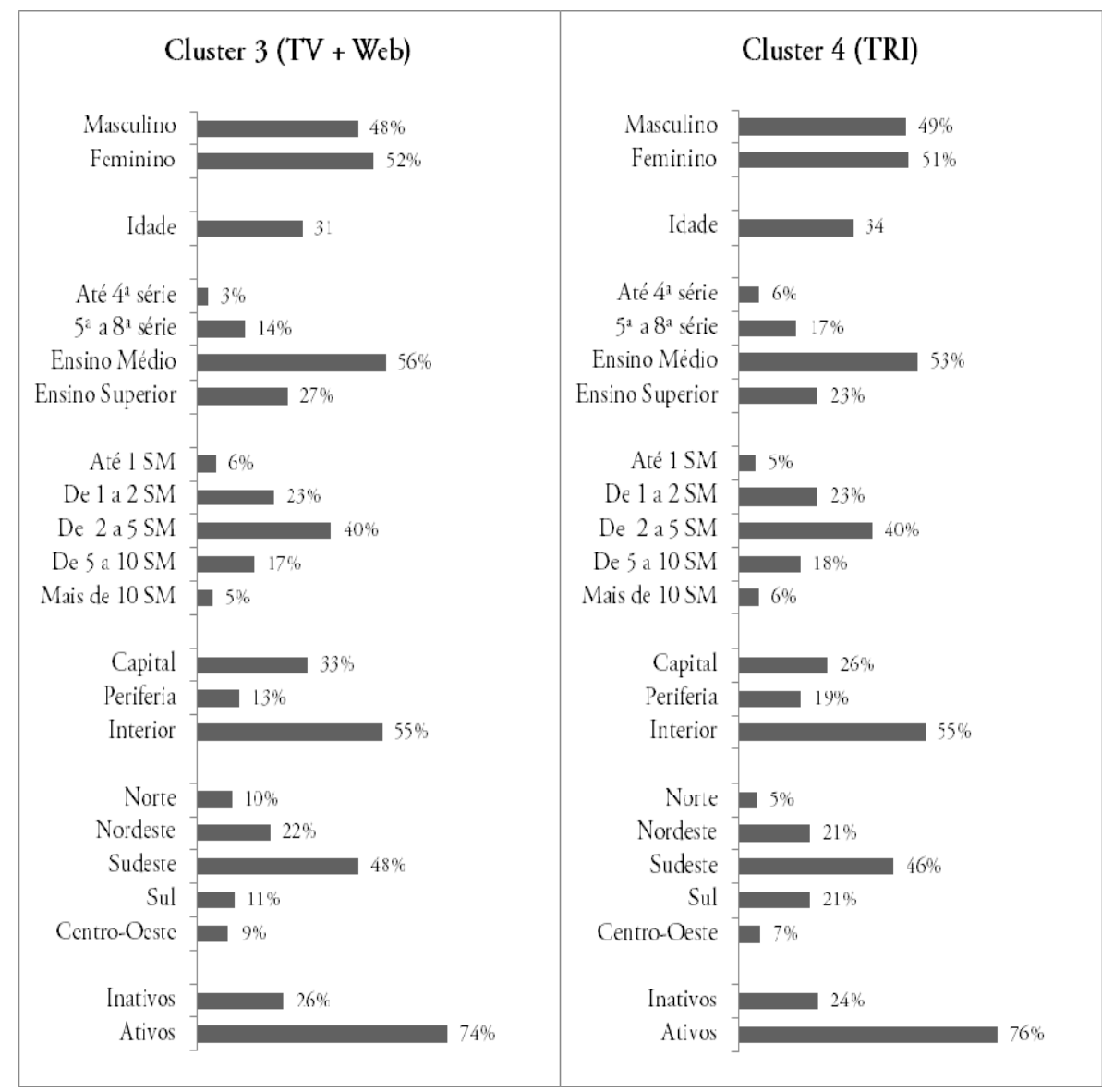


36 | Wladimir G. Gramacho e André Jácomo

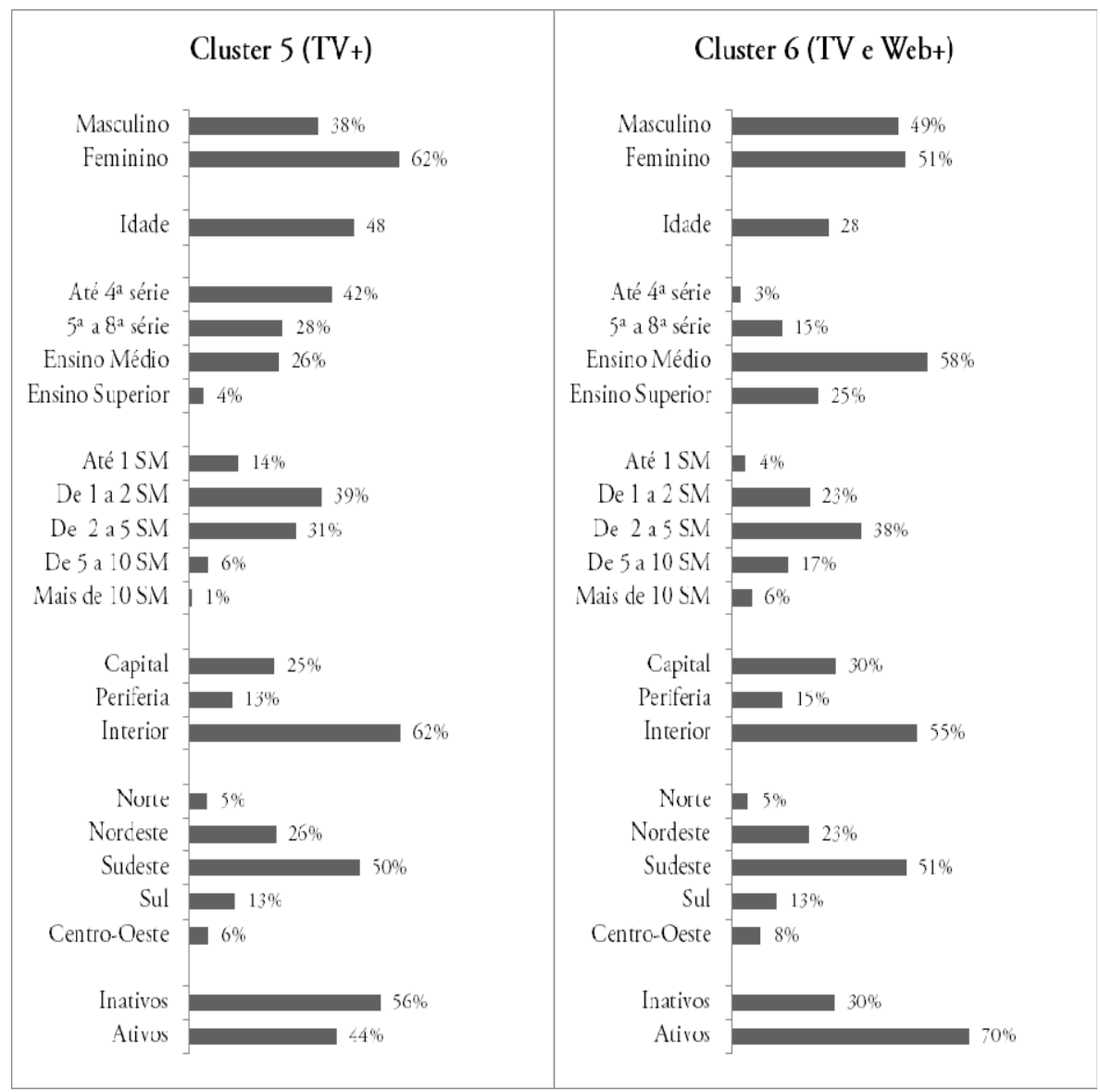

Fonte: Elaboração própria. 